Relations industrielles

Industrial Relations

\title{
Justice for all. An Introduction to the Social Teaching of the Catholic Church. By Rev. Benjamin L. Masse, s.j. The Bruce Publishing Company. Milwaulkee. 1964, 196 pp.
}

\section{Gérard Dion}

Volume 20, numéro 1, 1965

URI : https://id.erudit.org/iderudit/027561ar

DOI : https://doi.org/10.7202/027561ar

Aller au sommaire du numéro

\section{Éditeur(s)}

Département des relations industrielles de l'Université Laval

ISSN

0034-379X (imprimé)

1703-8138 (numérique)

Découvrir la revue

Citer ce compte rendu

Dion, G. (1965). Compte rendu de [Justice for all. An Introduction to the Social Teaching of the Catholic Church. By Rev. Benjamin L. Masse, s.j. The Bruce Publishing Company. Milwaukee. 1964, 196 pp.] Relations industrielles / Industrial Relations, 20(1), 200-200. https://doi.org/10.7202/027561ar

Tous droits réservés @ C Département des relations industrielles de l'Université Laval, 1965
Ce document est protégé par la loi sur le droit d'auteur. L'utilisation des services d'Érudit (y compris la reproduction) est assujettie à sa politique d'utilisation que vous pouvez consulter en ligne.

https://apropos.erudit.org/fr/usagers/politique-dutilisation/ 
qui militent dans quelque groupement que ce soit. II leur permettro de se situer de même que de mieux articuler leur action.

\section{Gérard DION}

Justice for all.An introduction to the social teaching of the Cotholic church. By Rev. Benjamin L. Masse, 5.j. The Bruce Publishing Compony. Milwaukee. 1964. $196 \mathrm{pp}$

Ce n'est pos une tôche focile de présenter en quelque deux cents poges les éléments fondamentaux de la doctrine sociale de $l^{\prime} E g l i s e$ et de jeter de la lumière sur les principaux problèmes concrets auxquels elle s'opplique. Un homme comme le R. P. Benjamin L. Masse pouvait relever ce défi. Depuis près de vingt-cinq ans rédacteur à la revue America, spécialiste dans les questions sociales, il a été amené d̀ analyser et à prendre position. II jouit universellement d'une réputation bien mérité.
L'outeur oborde successivement les sujets suivonts: Lo religion et l'économique; Les perspectives historiques; Le droit de propriété; Le solaire et lo justice; Une juste distribution pour tous; Le gouvernement et la vie économique; Le syndicalisme; Problèmes de relations industrielles; les paysons et la terre; Les nations riches et les nations pauvres; Vers la justice sociale. Dans un bref appendice, on trouve la liste des principaux ouvrages publiés en langue anglaise.

Cet ouvrage n'est pas fait pour les spécialistes qui veulent connaître tous les as. pects controversés des questions ni, non plus, pour les étudionts qui recherchent un manuel. II veut être simplement une introduction à l'enseignement social de l'Eglise appliqué oux conditions particulières que présente le contexte étatsunien et nord américain. Ainsi, il s'adresse ou public en général qui désire passéder certaines notions des implications de la doctrine catholique dans le domaine social.

Gérord DION

\section{PUBLICATIONS RÉCENTES RECENT PUBLICATIONS}

\section{Généralités}

«The Equalitarion Dream and Democratic Reality s by Dean Banks, The Freeman, Vol 14, No. 9 September 1964. pp. 22-32.

"L'automation: solut ou asservisement de I'humonité », par Pierre Bonnin, Chronique Sociale de France, Cohier 7, ler novembre 1964. pp. $405-417$.

"Pauvreté aux Etats-Unis », par H. Perroy, Revue de l'Action Populaire, No. 182, Novembre 1964, pp. 1043-1057.

"Le rôle des Etats-Unis et de l'Europe occidentale dans la conjoncture mondiale $»$, par Jean Morczewski, L'Actualité économique, No. 2, juillet-septembre 1964.

"L'Alliance pour le progrès a-t-elle un civenir", par R. Soez, Revue de l'Action Populaire, No. 181, septembre-octobre 1964, pp. 919-935.
«Cent ons d'Internationale Socialiste » por Carlo Schmid, Le Monde du Travail libre, No. 172, octobre 1964, pp. 6-12.

"An Appeal for Realism in Politics by $A$ Breton, C. Bruneau, Yvon Gauthier, M. Lolonde, M. Pinard and Pierre Trudeau. INFORMATION, United Steelworkers of America, Vol. 12, No. 3, June 1964, pp. 24-30.

" Mise sur pied d'un programme de recherche sur les applicotions futures de l'outomation", par John Diebold Travail et Méthodes, coût-septembre 1964, pp. 39-40.

"L'Automation", Conférence catholique conadienne, Documentation sociale, Document No. $73 ;$ i2. p. 1-6.

"Over Population Malnutrition and Birth Control " by Donald Barrett, Social Thought, Dec. 1, 1964, pp. 1-18.

"The Church and Social Policy», by Dr. Franz M. Muller, Social Thought, Series No. 8, 14, Oct. 1, 1964. pp. 1.10 